\title{
First generation Azerbaijani immigrants in the United States: socio-cultural characteristics and identity issues
}

\author{
Ahmad Guliyev \\ George Washington University, USA
}

\section{Introduction}

The United States continues to become more ethnically diverse with the increasing number of immigrants and minority residents. About 20 percent of all international migrants reside in the United States, which accounts for less than 5 percent of the world's population (Britz \& Batalova, 2013). Between the years 2000 and 2010, over 10 million foreign-born individuals moved to the United States. According to the American Community Survey (ACS), about 40.4 million foreign-born people lived in the United States in 2011 which constitutes 13 percent of the total population ${ }^{1}$. In other words, immigrants account for one in eight U.S. residents.

The community of Azerbaijani immigrants in the United States, which is the subject of our proposed study, is a pretty recent phenomenon. Most AzerbaijaniAmericans have immigrated to the United States mainly from Azerbaijan, Iran, Russia or Turkey. In fact, comparing to the most ethnic communities in the U.S., the Azerbaijani community in this country is both younger and smaller.

According to the 2000 U.S. census, there were an estimated 14,205 Americans born in Azerbaijan ${ }^{2}$. However, it is widely supposed that this figure is an undercount of the Azerbaijani American community. U.S. Census 2000 did not count Azerbaijani-Americans born in countries other than Azerbaijan. Unofficial estimates of the size of the Azerbaijani American community remained at around 400,000 (Mishory, 2006). Majority part of Azerbaijani community in the United States are comprised of ethnic Azerbaijani Turks migrated from Iran.

\footnotetext{
http://www.pewhispanic.org/files/2013/01/PHC-2011-FB-Stat-Profiles.pdf

2 "Table FBP-1. Profile of Selected Demographic and Social Characteristics". Census 2000 Special Tabulations (STP-159). U.S. Census Bureau. Retrieved 2012-11-17.
} 
The recent US Census 2010 didn't count residents of Azerbaijani descent. As there is no available recent US Census and American Community Survey data on Azerbaijani population, we have to refer to yearbooks of Immigration Statistics of Department of Homeland Security. According to DHS data, from 1992 to 2012 inclusive, a total of 28, 227 Azerbaijani immigrants were admitted ${ }^{3}$.

The topic of ethnic minorities and identity issues has been salient in literature as the numbers of immigrants continue to increase in the U.S. However, Azerbaijani immigration and integration in the United States have not been documented and studied thoroughly. Until now, Azerbaijani-Americans have been mainly neglected by academia.

The first comprehensive article about Azerbaijani-Americans appeared in the Harvard Encyclopedia of American Ethnic Groups in 1980 (Thernstrom et.al 1980) . In his article on Muslims in the United States, M. Arif Ghayur (1981) gave estimated number of Azerbaijani population and their major concentration in 1980 .

In a few studies (Naoki, 2001; Mostofi, 2003; Darya, 2006; Hakimzadeh, 2006) on Iranian - Americans, Azerbaijanis were briefly mentioned as a part of Iranian immigrant population. Few notes on Azerbaijani Diaspora in the USA were appeared in a book titled "Central Asia and the Caucasus: Transnationalism and Diaspora" (Atabaki \& Mehendale, 2005). Another challenge is that, most of the research on post-Soviet immigrantsprincipally focused on the Russian and Ukrainian immigrants in the United States. Even some of these researches refer to the immigrants from the former Soviet Union as "Russian" despite the fact that this is a heterogeneous and multilingual group of people. This reference also causes a great deal of confusion. Recently, Ramazan Uslu and Sinan Kocaman (2013) briefly gave an overview of Azerbaijani diaspora in U.S in terms of political activism.

So far, there has been little discussion about Azerbaijani immigrants in the United States among Azerbaijani scholars. In his paper, Dr. Javid Huseynov (2008) explored the role of online communities in the development and formulation of Azerbaijani national identity. Lala Hajibayova (2012), alumni of Indiana University, Bloomington, in her article focused on online representation of the

\footnotetext{
${ }^{3}$ Source: U.S. Department of Homeland Security.
} 
Azerbaijani Diaspora through ethnographic research of the most popular listserves, forums and websites In addition, there exists scanty non-academic literature (Naghiyeva and Hasanov, 2006) that offers brief information on AzerbaijaniAmericans.

There is no special work devoted to the study on Azerbaijani immigrants in the United States. Therefore, there is need to analyze how Azerbaijani immigrants in the United States view themselves, how and with what methods they have created an identity and whether or not they have been successful in creating a community within the American civil society context.

The main aim of the proposed research project is to explore how has the experience of living in the United States as an ethnic minority influenced Azerbaijani immigrants' consciousness, in terms of their ethnic identity and examine sociodemographic characteristics of Azerbaijani population in the United States based on the results of the web survey of Azerbaijani community and US federal statistics on international migration.

\section{Methodology}

There is no population survey that provides information of any kind on the attitudes and opinions of Azerbaijani Americans. We developed and conducted an online survey with 103 respondents (51 men and 52 women). An online questionnaire $^{4}$ with 20 questions was designed in order to understand the different aspects of the community, socio-cultural characteristics, assess the Azerbaijani immigrant's identification with Azerbaijani culture, ethnic attachment, as well as, their emotional ties to the homeland, and level of integration in the United States. Another objective was to bring perspectives from different groups within the Azerbaijani-American community. Survey questionnaire is included in Appendix A.

The participants were reached through list serves and Facebook pages of Azerbaijani American organizations in New York City, Houston (Texas), Irvine (California), Miami (Florida) and Chicago (Illinois). An e-mail including a brief introduction to the study and the link to the surveys was sent to the list-serves. Some of these lists serves included: Azeris@googlegroups.com (about more than

\footnotetext{
${ }^{4}$ https://www.surveymonkey.com/s/6CN3SWH
} 
500 Members); HoustonAzeris@yahoogroups.com (about 132 Members); AzeriChicago@yahoogroups.com (about 72 Members); AzeriMN@yahoogroups.com (about 52 Members).

The same e-mail was also sent to different Azerbaijani American organizations. In this brief introduction, the representatives of these organizations were asked to forward the study to their members and other Azerbaijani people they knew. Additionally, a link to the online study was posted on Facebook pages of Azerbaijan Cultural Center in New York City, Azerbaijani American Women's Association of New-York, Texas Azerbaijanis, The Azerbaijani American Cultural Association of Florida and "Every Azeri" (online magazine established by a group of Azerbaijani American immigrant women).

\section{Criteria for Participation}

Eligible participants were required to meet the following criteria: 18 years of age or older, U.S. born, or naturalized citizens of Azerbaijani decent, Lawful permanent residents, other Azerbaijani immigrants who have been living in the United States for at least five years.

\section{Participants}

Our sample was a random, and covered a wide range of Azerbaijanis regarding age groups, education levels, length of stay and geographic distribution in the United States. A total of 103 Azerbaijani Americans participated in the survey. Among participants, 51 (49.5\%) were male and 52 (50.5\%) were female. Except one respondent, all of survey participants are foreign-born, as well as the firstgeneration immigrants $(99.03 \%)$.

The vast majority of the respondents (93.2\%; $\mathrm{N}=96)$ were born in Azerbaijan. Small percentages $(2.9 \%)$ were born in Georgia, and the remaining $3.9 \%$ born in the USA, Turkey, Armenia and Uzbekistan.

Although, more than three-fourths of the participants $(75.5 \%)$ reported living in the state of Texas $(43 \% ; N=44)$, New York $(18.6 \% ; N=19)$, California $(9.8 \% ; \mathrm{N}=$ $10)$, and Maryland $(3.9 \% ; N=4)$ participants lived in 22 states and territories of the United States. 
Ahmad Guliyev

Half (50 percent) of the respondents are Naturalized U.S. Citizens, 37 percent are Permanent residents, 12 percent have student visas and the remaining 1 individual is a U.S. citizen of Azerbaijani ancestry, born in the U.S. One respondent skipped over the question. $73 \%$ of the respondents, 25 years and older have a Bachelor's or graduate degree, and 16 percent hold a doctoral degree. The majority group of respondents had been residing in the United States for 5-9 years (55.54 percent), with a remaining 44.5 percent having been resident more than 10 years.

\section{Research findings}

Age at Immigration and Length of Residency in the United States

Demographic characteristics of our sample indicate that a majority of the Azerbaijani immigrants are relatively younger generation. Respondents' the mean age are 37 years with a range of between 18 and 74 years. The average length of stay of the respondents in the United States is 10 years. Only 9.9 percent of the respondents reported their length of staying 20 and more years $(N=10)$. Two respondents skipped over the question

Our study reveals that length of residency in the United States has an influence on ethnic identity and English proficiency of respondents. However, in term of ethnic identity, among those who came to United States at 40 years of age or later, the years spent in United States had no significant effect on their sense of identity and majority of them identified themselves as Azerbaijani than Azerbaijani-American or American.

\section{Reasons for Immigration}

The main reasons for emigration among the respondents include family reunification, a higher standard of living, and better educational opportunities. 39 percent of the respondents moved to the United States mainly due to family reasons $(N=39) ; 34$ percent moved for educational purposes $(N=34) ; 26$ percent have immigrated to seek better occupational opportunities $(N=26)$. Only one respondent $(1 \%)$ indicated political motive as reason of immigration. Three respondents skipped over the question. 
Our study reveals difference between men's and women's migration determinants. Women (52.9\%) in our study are more likely to immigrate for family reasons whereas the majority of men moved in search of better educational opportunities (49\%) and employment (24.5\%).

\section{Educational attainment}

Of those surveyed 25 years and older, $16 \%$ reported having a doctoral degree, $(N$ $=13), 62 \%$ graduate degree $(N=52), 21 \%$ having a bachelor's degree $(N=18)$, and only one respondent $(1 \%)$ reported having a high school diploma. To sum up, $99 \%$ of respondents had a Bachelor's degree or higher. This numbers are much higher than US Census 2000 data where the 46.7 percent of Azerbaijani Americans 25 years and older had a bachelor's degree or higher, compared to 25.6 percent of native-born adults and 25.8 percent of all foreign-born adults ${ }^{5}$.

Survey results confirm the fact, that Azerbaijani Americans are one of the highly educated ethnic groups in the United States. It should be noted that, educational attainments of Azerbaijani Americans greatly surpass the US national average. According to U.S. Census Bureau, Current Population Survey 2012, $30.9 \%$ of U.S. population 25 years and older have bachelor's degrees or higher.

The educational level of our sample offer further testimony for the argument that recent Azerbaijani immigrant group mostly consists of highly educated and skilled professionals. This fact can be considered as a sign of ongoing "brain-drain" from Azerbaijan. It is widely accepted that, immigrants who have high levels of educational and occupational attainment as well as English proficiency are likely to integrate rapidly into American society. According to report on immigrant assimilation in the United States issued in 2008, Azerbaijani immigrants experience high rates of economical assimilation rather than cultural ${ }^{7}$.

\footnotetext{
5 "Table FBP-1. Profile of Selected Demographic and Social Characteristics". Census 2000 Special Tabulations (STP-159). U.S. Census Bureau. Retrieved 2013-11-17

${ }^{6}$ Source: U.S. Census Bureau, Current Population Survey, 2012, Historical Educational Attainment Visualizations. http://www.census.gov/hhes/socdemo/education/data/cps/historical/tabA-4.xls

${ }^{7}$ Jacob Vigdor, Measuring Immigrant Assimilation in the United States Manhattan Institute for Policy Research, Civic Report, No. 53 May 2008, p..35. http://www.manhattaninstitute.org/html/cr 53 ail.htm
} 
Ethnic self-identification

While scholars have differing ideas on the components of the ethnic identity concept, it is widely believed that self-identification as a member and a sense of belonging to the group are the basis for ethnic identity. According to the widely accepted definition of ethnic identity which was developed by Jean Phinney, "ethnic identity is a dynamic, multidimensional construct that refers to one's identity or sense of self as a member of an ethnic group" ${ }^{8}$. There is also no agreement among scholar how to measure ethnic identity. Self- identification is one of the ways to measure ethnic identity among immigrants which maintained by Stephan (Stephan and Stephan, 2000) as "the most appropriate means of measurement for both research and social categorization".

Respondents were asked to identify with one of the following four categories: "Azerbaijani," Azerbaijani-American," American," and "other. It should be noted that, regardless of the length of their stay in the U.S. that most of these individuals identified themselves as Azerbaijani, rather than Azerbaijani-American or American. More than half of the respondents (58\%) identified themselves as "Azerbaijani," about the third (34\%) as "Azerbaijani-American," and only 2 percent as American. The remaining 6 percent chose "other" (Figure 1).

The findings of our study show that, majority of established immigrants (those who have lived in the United States for 20 years and more) tended to identify themselves Azerbaijani-American than Azerbaijani. At the opposite end, more than two-thirds (71\%) of the relatively new immigrants, who have lived in the United States for 5-14 years, considered themselves as Azerbaijani.

Research also has revealed some correlation between legal status and selfidentification among participants. If the naturalized US citizens tended to consider themselves as equally Azerbaijani or more Azerbaijani-American, overwhelming majority (73.7\%) of LPRs are more likely to identify themselves as Azerbaijani.

\footnotetext{
${ }^{8}$ Phinney, J. (2003). Ethnic Identity and Acculturation. In K. Chun, P. Ball, \& Marin, G. (Eds.), Acculturation: Advances in theory, measurement, and applied research (pp. 63-81) Washington, DC: American Psychological Association., p.63.

${ }^{9}$ Stephan, C. W., and W. G. Stephan. 2000a. The Measurement of Racial and Ethnic Identity. International Journal of Intercultural Relations 24: 541-552, p. 547
} 


\section{Figure 1. Ethnic self-identification}

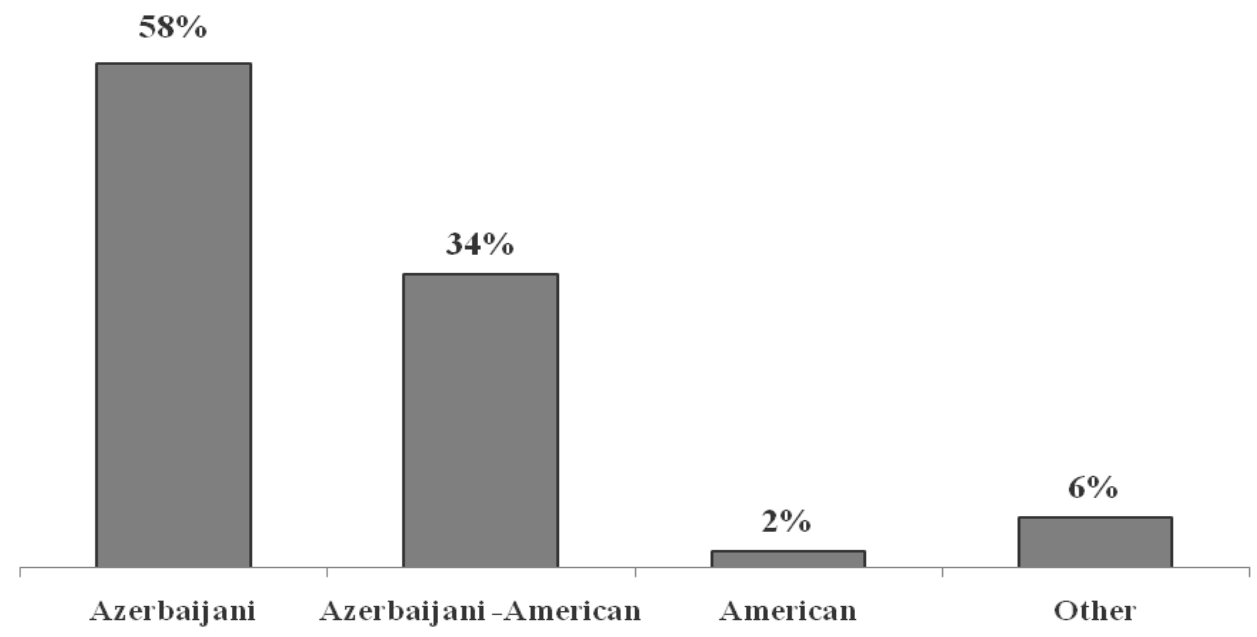

It has been suggested that, length of stay in host country and age at immigration are among the factors influencing immigrants' ethnic identity (Kuo, B. C. H., \& Roysircar, G. 2004; 2006; Schönpflug, U. 2002; Ng \& Northcott, 2010; Rivers N, 2012).

Two-thirds of respondents who reported speaking English regularly at home were more tended to identify themselves as Azerbaijani-American than were those who reported speaking Azerbaijani or Russian at home setting.

\section{Languages spoken at home}

Many scholars suggest that, language is one of the important indicators of ethnic and cultural identities (Taylor, et al., 1973; Giles, et al., 1976; Giles, H., Bourhis, R. Y. \& Taylor, D. 1977; Fishman, 1999) among immigrant groups. Positive correlation between proficiency in native language and ethnic identities has been shown by previous studies (Gudykunst, W. \& Schmidt, K. 1987; Gudykunst 2001; Chinen and Tucker 2005; Pigott and Kalbach, 2005). Especially, Gudykunst, W. \& Schmidt maintained that, "language and ethnic identity are related reciprocally, i.e. language usage influences the formation of ethnic identity, but ethnic identity also influences language attitudes and language usage" ${ }^{\prime 10}$. Speaking the ethnic language

10 Gudykunst, W. B., Schmidt, K. L. (1987) Language and Ethnic Identity: An Overview and Prologue. Journal of Language and Social Psychology. Vol. 6, Nos. 3 and 4, 157-170, p.157. 
allows group members to create and maintain links in the ethnic community, as well as to connect with family and friends in the country of origin.

Majority of respondents (55\%) report that they primarily speak Azerbaijani at home. $16 \%$ of the respondents communicate in English. It's not surprising that, Russian is a language of communication in $27 \%$ of homes (Figure 2). Majority of Azerbaijani immigrants especially who went through the Soviet education system can speak Russian which was widely taught in the schools. Nowadays, some people in capital city of Baku use Russian also in home settings.

Figure 2. Languages spoken at home

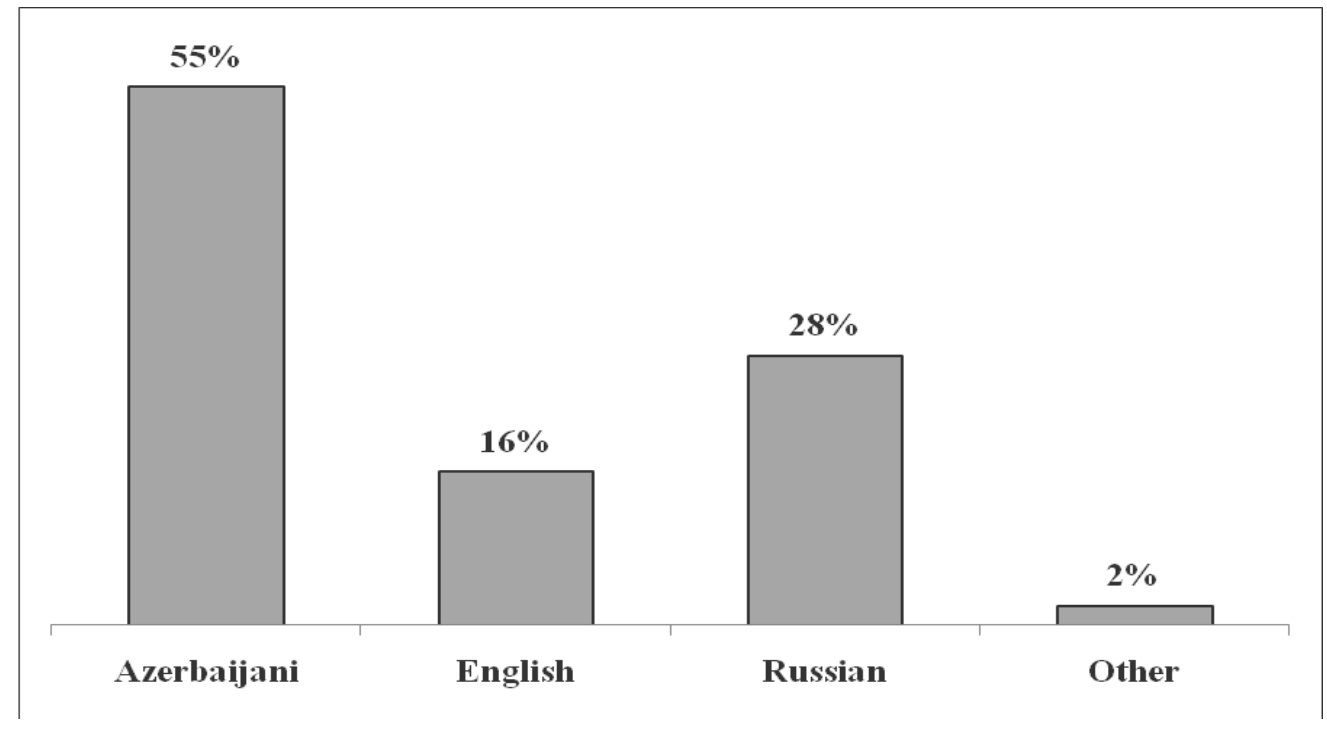

Use of English at home is more widespread among immigrants who have been in the United States longer. One-thirds (33\%) of those who have been in the country for 15 years or more speak only English at home, compared with $12 \%$ of those who arrived in the less than 15 years. According to US Census 2002 data, only 3 percent of immigrants born in Azerbaijan (5 years and older) spoke English at home ${ }^{11}$.

Speaking the native language frequently in the home is significantly related to one's ethnic identity. The more respondents speak Azerbaijani at home, the more likely they were to identify themselves as "Azerbaijani. More than two-thirds of

\footnotetext{
${ }^{11}$ http://www.census.gov/population/cen2000/stp-159/STP-159-Azerbaijan.pdf
} 
respondents (64.4\%) reported speak Azerbaijani at home were those who identified themselves as "Azerbaijani.

\section{Parent's role in language maintenance}

The maintenance of a native language across generations requires that the language be passed from parents to children. In the US context, transferring of native language to further generations involves challenges. For Azerbaijani ethnic language speakers, the primary domain to maintain Azerbaijani is in the family. According to Farver (2002), "as a primary socializer of children, the family may be the first influence on adolescents' ethnic identity".

The essential role of parenting behaviors in a child's identity development has been suggested by previous research (Farver, et al., 2002; Abad \& Sheldon, 2008; Su \& Costigan, 2009; Voutsinas, 2012). Parents can serve as language teachers and models at home, mainly through using native language as the medium of communication and the possibility of heritage language maintenance depends on both parents and children. However, speaking native language at home is not sufficient for full acquisition and maintenance of it. Another factors having positive influence in language maintaining are following ethnic media, visits to homeland, participation in cultural and social activities associated with ethnic culture and community.

About half of the parents (49\%) reported using the Azerbaijan language when communicating with the child at home. More than a quarter (26\%) of respondents speaks English and 23 percent speak Russian with their children. The remaining 1 individual (1\%) chose "other" language.

Proficiency in native language is likely to be another factor in retaining ethnic identity. Majority of those (53 percent) who identified themselves as "Azerbaijani" or "Azerbaijani-American" reported speaking Azerbaijani with their children. Comparatively, 2 respondents who identified themselves American use Russian in conversations with their children.

After Azerbaijani (48\%) English (27\%) and Russian (23\%) are almost equally common among naturalized citizens when speaking with their children. We see the same situation with LPRs but with slight difference, 55\% of permanent residents 
use Azerbaijani, 26\% Russian and $19 \%$ English in conversations with their children.

In spite of challenges in maintaining heritage language in diverse US society, the majority of our respondents are likely to speak Azerbaijani with their children to enable them to learn and understand the Azerbaijani culture and traditions.

\section{English Language Proficiency}

Previous research has shown that like education, English language ability positively influences labor market outcomes and social and cultural integration in the United States (Chiswick, 1999; Chiswick \& Miller 2007; Chiswick, 2008).

It is widely recognized that, English language proficiency is highly correlated with educational achievement. Being one of the educated immigrants groups, Azerbaijani immigrants are likely to report high English skills. Nearly two-thirds (64 percent) of respondents reported speaking English "very well" and 32 percent reported speaking English "well" and only, 4 percent reported that they speak "poor" English.

Generally, 96 percent of the surveyed reported speaking English "well" or "very well". This figure is much higher in comparison with US Census 2000 data on English proficiency among a sample of Azerbaijani immigrants. Based on US Census 2000 data, MLA Language Map Data Center provided the English proficiency results for a sample of 318 Azerbaijanis in the US. According to the results, of 318 respondents, 200 reported speak English "well" or "very well" (63\%). The remaining 118 (38\%) reported speak English "not well" or "not at all"12.

Length of residency in the United States and English proficiency has positive correlation. Of respondents who have lived in the United States for at least 6 years and more, two-thirds (66\%) reported speaking English very well. For relatively recent arrivals (those who have lived in the United States for 5 years) $56 \%$ reported speaking English very well.

\footnotetext{
${ }^{12}$ Source: Census 2000, Summary File 3 STP 258 http://www.mla.org/map_data_results\&SRVY_YEAR=2000\&geo=\&state_id=\&county_id=\&m ode=lang_tops\&lang_id=690\&zip $=\& p l a c e \_i d=\& c t y \_i d=\&$ region_id=\&division_id=\&ll=\&ea=y\&ord $\underline{\mathrm{er}=\& \mathrm{a}=\mathrm{y} \& \mathrm{pc}=1}$
} 
The younger the respondents, the more likely they are to report higher English proficiency. The 81 percent of age cohort 18-44 say they speak English very well, compared with a 39 percent of those 45 years old and above.

Naturalization process itself entails immigrant's ability to speak and read English. With some exception, LPRs who want to be naturalized need to demonstrate a required level of English language proficiency which prompts them to improve their language skills.

\section{Membership in ethnic associations}

Along with native language proficiency, participating in the ethnic community is important in maintaining ethnic identity. Ethnic identity sometimes is created through community and familial ties rather than through actual ethnic heritage (Kelly, 1996). Diaspora organizations which serve as important function for communication and social mobilization among Azerbaijani immigrants are widely considered as the building blocks of Azerbaijani community in the United States. These organizations provide group members with opportunities to engage in ethnic culture which contribute to maintaining ethnic identity.

More than two-thirds (69\%) of the respondents or 71 individuals reported belonging to any Azerbaijani organization in the USA (Figure 3). The youngest age cohort (18-24) has the relatively lowest membership percentage (53\%) in comparing with elder age groups. With 82 percent, the age cohort 25-34 has the highest membership rate in ethnic organizations.

\section{Figure 3. Membership in ethnic associations}

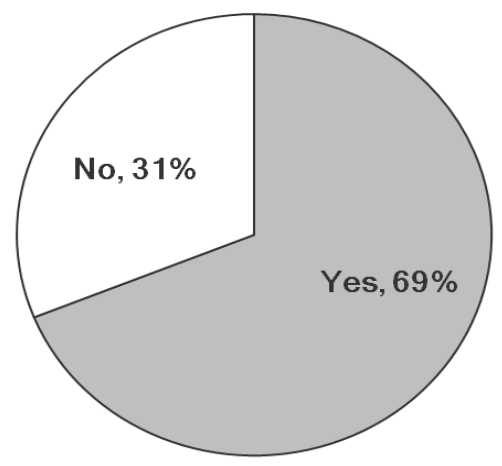


Length of stay has also positive influence on membership in ethnic organizations. More than three-fourth (76\%) of those who have been in US for 6 years or more reported affiliation with any Azerbaijani organization, compared with 58\% of those who have been lived in the country in the past 5 years. Female representation (71\%) in diaspora organizations is slightly higher comparing with male (67\%).

\section{Cultural Retention and Practices}

In addition to self-identification as a member and a subjective sense of belonging to the group, ethnic identity can be expressed in behaviors such as cultural practices (Phinney 2003; Phinney and Ong 2007). According to Phinney, "involvement in the social life and cultural practices of one's ethnic group is the most widely used indicator of ethnic identity" ${ }^{13}$. Previous research suggests positive correlation between cultural practices and ethnic identity (Rosenthal and Feldman 1992; Schweigman, et al. 2011). Some of the most common measures include various cultural activities such as, music, dance, reading, attire, cuisine, and traditional celebrations (Phinney 1990). In our study, cultural retention among participants was gauged by frequency of participation in traditional celebrations and listening to ethnic music and watching movies.

Majority of respondents (51\%) reported attending Azerbaijani events, occasions and holidays "always" and "often". Nearly one in three (29\%) is likely to attend "sometimes" and small percentage of respondents (17\%) tended to attend community events "rarely". In festivities, especially in Novruz and New Year celebrations Azerbaijani immigrants get together. Residential concentration and proximity to ethnic organizations have also considerable impact on frequency of immigrant membership and participation in community.

44 percent of respondents reported that they listen to Azeri music and watch Azeri movies daily or often, 29 percent "sometimes", 23 percent of participants reported "very rarely. Only 4 percent chose "never".

The more respondents were engaged in cultural activities, the more likely they were to identify themselves as either "Azerbaijani or "Azerbaijani - American." Commitment to the maintenance of ethnic identity can easily be seen among the

\footnotetext{
${ }^{13}$ Phinney, J. S. (1990). Ethnic identity in adolescents and adults: Review of research. Psychological Bulletin, Vol. 108(3), 499-514.p.505.
} 
majority of the respondents. In general, Majority of Azerbaijani immigrants make an effort to retain their native culture.

\section{Participation in U.S. Society: Citizenship}

Azerbaijani immigrants in U.S. are educated and more likely to integrate to American culture. The study finds that the, while maintaining their culture, Azerbaijani Americans seek involvement with the American society and culture. Definitely, proficiency in English serves as an important means of instrumental integration into American society.

In spite of cultural differences between Azerbaijanis and Americans, Azerbaijanis do not suffer from culture shock and conflict. Despite the evident resistance to linguistic assimilation, Azerbaijanis are interested in the American culture; vast majority of the respondents (92\%) celebrate American holidays.

According to MIPEX (a project is led by the British Council and the Migration Policy Group) he US has some slightly favorable policies to encourage immigrants to participate and become full citizens. MIPEX results put the US at 9th place compared to 29 European countries and Canada ${ }^{14}$.

Survey data are used to determine citizenship status has a positive effect on host culture adoption. There is a positive relationship between naturalization and the degree of host culture adoption. Citizenship status has been shown to significantly predict an integrated identity with the host country. Half of our respondents (50\%) had acquired US citizenship. In our survey majority of naturalized Azerbaijani immigrants showed a bicultural identity, better English language proficiency (98\% reported speak English well or vey well), and higher educational attainment (71\% reported having masters' or doctoral degrees) than non-naturalized Azerbaijani immigrants.

The degree of socialization with Americans is also indicator of integration and adaptation to mainstream culture. Majority of respondents (43\%) reported sociallizing with equally both Americans and Azerbaijanis. Small percentages (4\% and $1 \%$ ) of respondents reported spending their time with only Azerbaijani and Ameri-

\footnotetext{
${ }^{14}$ The Migrant Integration Policy Index (Mipex III) http://www.mipex.eu/usa
} 
can friends respectively. Students $(42 \%)$ are more like to interact mostly with Americans compared with $35 \%$ of naturalized citizens and $16 \%$ of permanent residents.

Figure 4. People whom respondents socialize with in the US

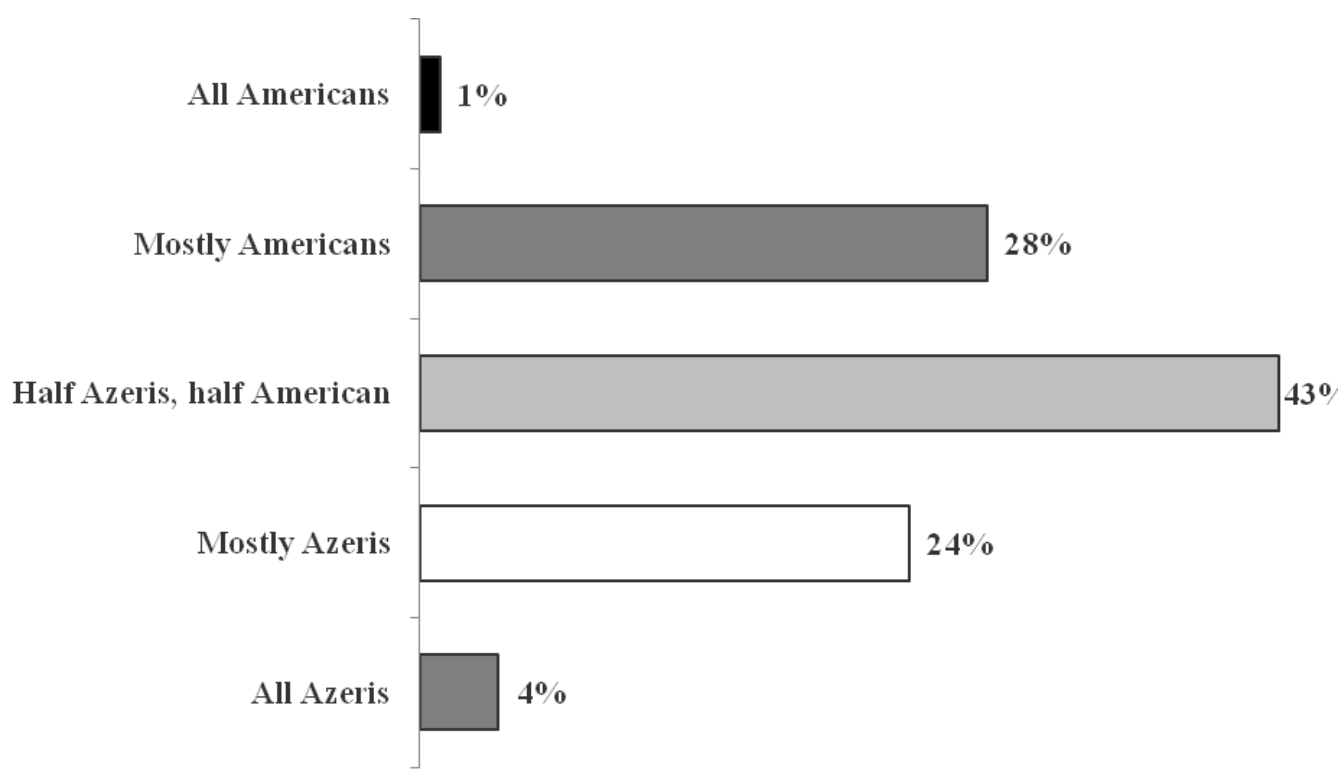

Transnational Ties: Visits to Homeland

The positive correlation between transnational ties with the immigrants' countries of origin and ethnic identity has been suggested by previous research (Murphy and Mahalingam 2004; Somerville 2008; Vaquera \& Aranda 2011). Transnational ties involve communicating with family, friends, and relatives in the home country, visiting them in the home country, or having them visit in the new country (Foner 2001; Ng, Cheuk Fan et.al, 2010). Visits to homeland create opportunities for immigrant's exposure to native speakers and culture. Transnational connections have significant bearing on the culture and identity of the second generation immigrants (Vertovec, 2001).

Overwhelming majority (89\%) of our respondents reported visiting their homeland occasionally to frequently 2.28 times on average in the past five years. Most of the respondents (36\%) have been to Azerbaijan between 2 or 3 times followed by $32 \%$ 
of respondents who have visited their native country once. $12 \%$ of respondents reported visiting their homeland 4-5 times in the last five years (Figure 5).

\section{Figure 5. Frequency of visits to homeland in the past 5 years}

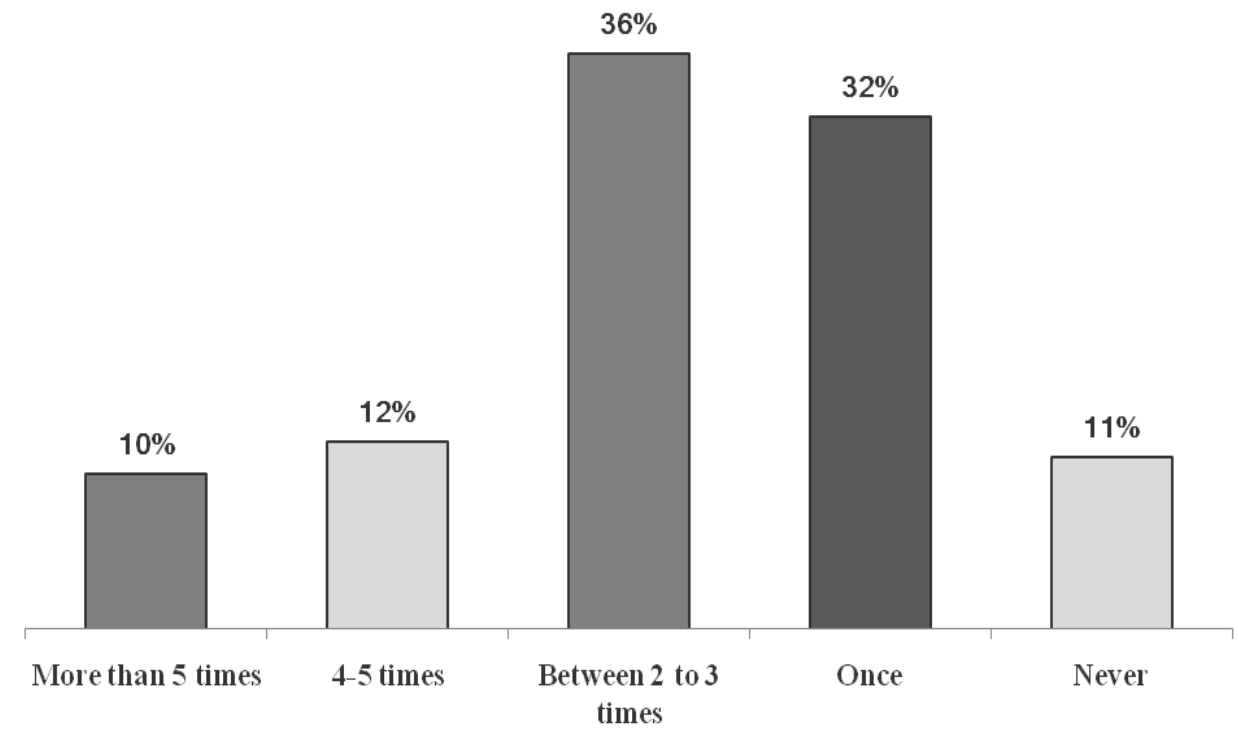

A quarter of students are more likely to visit their homeland frequently more than 5 times in the in the past five years compared with $13 \%$ of permanent residents and $4 \%$ of naturalized citizens.

There is some correlation between length of residence in the host country and frequency of visits to homeland. Our study reveals that, respondents who have a longer time of residence in the United States tended to visit their homeland less frequently. 44 percent of respondents who have lived in the United States for 15-19 years have visited their native country once. Of respondents who have lived in the United States for more than 20 years, $60 \%$ have not visited their homeland in the last five years.

The results of the current study indicate that, majority of the respondents maintained transnational ties to their homeland through visiting with their families and friends. 


\section{Media}

Azerbaijani language media is also one of the important means linking Azerbaijani immigrants to their homeland. Our respondents have strong interest and concern for Azerbaijani affairs and political developments in the homeland. Almost twothirds of respondents (65\%) closely follow socio-political developments in Azerbaijan on daily basis or several times a week. This percentage is higher among those who identified themselves either "Azerbaijani" or "Azerbaijani American" with $67 \%$ and $69 \%$ respectively. Only $15 \%$ of respondents follow news about their homeland rarely.

Azerbaijani language media (Satellite TVs, radio, digital media), in some degree serve role essential to identity construction among Azerbaijanis in US through connecting community members to their cultural roots. The findings of this research show that, vast majority of respondents (82\%) get the majority of their information about Azerbaijan from Azerbaijani sources. For Azerbaijani immigrants native language media is also positively related with maintaining native language which is one of the major makers of ethnic identity. Azerbaijani language media comprises the significant part $(67 \%)$ of news sources of our respondents. The more respondents were spoken Azerbaijani at home, the more likely they were to get homeland related news Azerbaijani language media. $73 \%$ of the respondents who reported speak Azerbaijani at home get news about Azerbaijan from Azerbaijani language sources.

\section{Figure 6. Sources of news about Azerbaijan}

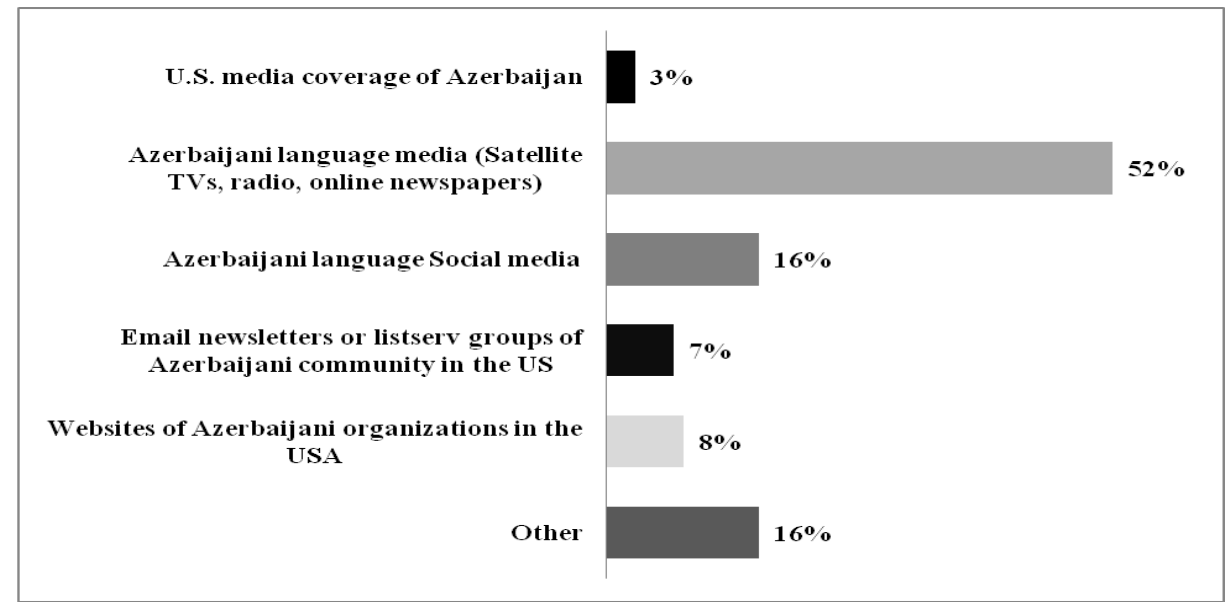


Azerbaijani language satellite TVs, radio and online newspapers serve as the largest source of news about Azerbaijan (52\%) followed by social media with 16\%. $15 \%$ reported web-sites, e-mail newsletters and listservs of Azerbaijani-American organizations as their news source. 16\% are more likely to get news about Azerbaijan from other sources. Only 3\% turn to the US media as their news source on Azerbaijan (Figure 6).

The younger cohorts are more likely to get their news about Azerbaijan via social media than elders. $88 \%$ of respondents who use social media a news source are individuals 18-44 years old.

\section{Conclusions}

The community of Azerbaijani immigrants in the United States, which is the subject of our proposed study, is a pretty recent phenomenon. In fact, comparing to the most ethnic communities in the U.S., the Azerbaijani community is both younger and smaller. Until now, Azerbaijani-Americans have been mainly neglected by academia.

Demographic characteristics of our sample indicated that a majority of the Azerbaijani immigrants are relatively younger generation. Survey results confirm the fact, that Azerbaijani Americans are one of the highly educated ethnic groups in the United States, greatly surpassing the US average. It should be noted that, regardless of the length of their stay in the U.S. most of these individuals identified themselves as Azerbaijani, rather than Azerbaijani-American or American.

The survey also showed that, our respondents have strong interest and concern for Azerbaijani affairs. The more respondents were spoken Azerbaijani at home, the more likely they were to get homeland related news Azerbaijani language media. Majority of them are members of Azerbaijani organization. They maintain connection with their homeland and overwhelming majority of our respondents has visited their homeland in the past five years. Our study reveals that the, while maintaining their culture, Azerbaijani Americans seek involvement with the American society and culture. Azerbaijani immigrants are generally inclined toward integration into the American society. 


\section{Acknowledgments}

I am very grateful to the Fulbright Commission for supporting my research in the United States. I would like to thank the Institute for European, Russian and Eurasian Studies at George Washington University for hosting me during my research in Washington DC. I owe my deepest gratitude to my supervisor, Professor Peter Rollberg for his support and scholarly advice. I am extremely thankful to Dr. Sufian Zhemukhov, a PONARS Eurasia Fellow for his invaluable suggestions and constant encouragement. I wish to show my high appreciation to the Azerbaijani community in the United States, particularly, to the chairwoman of Azerbaijani American Women's Association of New-York Ms. Minavvar Vahabova, Texas Azerbaijanis, Mr. Elkhan Agamirza, Azerbaijan Cultural Center in New York City and Azerbaijani-American Council.

\section{References and notes:}

Abad, N. S., \& Sheldon, K. M. (2008). Parental autonomy support and ethnic culture identification among second-generation immigrants. Journal of Family Psychology, 22, 652-657.

American Community Survey (ACS),

Andrews, D. (1999). Sociocultural perspectives on language change in Diaspora: Soviet immigrants in the United States. Amsterdam: J. Benjamins.;

Atabaki T, \& Mehendale S. (2005). Central Asia and the Caucasus: transnationalism and diaspora. Routledge.

Britz E. and Batalova J.(2013) Frequently Requested Statistics on Immigrants and Immigration in the United States. Migration Policy Institute. http://www.migrationinformation.org/USfocus/display.cfm?id=931\#11

Census 2000 Special Tabulations (STP-159). "Table FBP-1. Profile of Selected Demographic and Social Characteristics". U.S. Census Bureau. Retrieved 2012-11-17.

Chinen K. G. \& Tucker R. (2005). Heritage Language Development: Understanding the Roles of Ethnic Identity and Saturday School Participation Heritage Language Journal 3.1 Fall, pp.27-59.

Chiswick, B. R. \& Miller, P. W. (2007). "Matching Language Proficiency to Occupation: The Effect on Immigrants' Earnings," IZA Discussion Papers 2587, Institute for the Study of Labor (IZA). http://ftp.iza.org/dp2587.pdf

Chiswick, B. R. (1999). "Are Immigrants Favorably Self-Selected?" American Economic Review, 89(2): 181-185.

Chiswick, B. R. (2008). "The Economics of Language: An Introduction and Overview," IZA Discussion Papers 3568, Institute for the Study of Labor (IZA). http://ftp.iza.org/dp3568.pdf 
Darya, F.(2006). Second-generation Iranian-Americans: The relationship between ethnic identity, acculturation, and psychological well-being (Ph.D. dissertation). Capella University, Retrieved from ProQuest. http://search.proquest.com/docview/304722563.

Farver, J. A., Narang, S. K., \& Bhada, B. R. (2002b). East Meets West: Ethnic identity, acculturation, and conflict in Asian Indian families. Journal of Family Psychology, 16, $338-350$.

Fishman, J. (1999). Handbook of Language and Ethnicity (ed.). New York, Oxford University Press.

Foner, N. (2001). West Indian Migration to New York: An Overview. In Islands in the City, ed. Nancy Foner, 1-22. Los Angeles: University of California Press.

Ghayur A. M.. Muslims in the United States: Settlers and Visitors. Annals of the American Academy of Political and SocialScience, Vol. 454, America as a Multicultural Society (Mar., 1981), pp. 150-163. URL: http://www.jstor.org/stable/1044252 Accessed: 10/10/2013 11:34.

Giles, H., Bourhis, R.Y. \& Taylor, D.M. (1977). Towards a theory of language in ethnic group relations. In H. Giles (ed.): Language, Ethnicity and Intergroup Relations. London, Academic Press, pp. 307-348.

Giles, H., Taylor, D.M., Lambert, W.E. \& Albert, G. (1976) Dimensions of ethnic identity: An example from Northern Maine. Journal of Social Psychology, 100, 11-19.

Gudykunst, W. B. (2001). Asian American ethnicity and communication. Thousand Oaks, CA: Sage.

Gudykunst, W. B., Schmidt, K. L. (1987) Language and Ethnic Identity: An Overview and Prologue. Journal of Language and Social Psychology. Vol. 6, Nos. 3 and 4, 157-170.

Hajibayova, L. (2012) “Online Representation of Azerbaijani Online Community”. Khazar Journal of Humanities and Social Sciences. Baku, Volume 15, Number 4, 2012, pp-3449. http://jhss-khazar.org/wp-content/uploads/2012/12/3-meqale-lala.pdf (Retrieved on 2013-12-09).

Hakimzadeh, Sh. (2006), "Iran: A Vast Diaspora Abroad and Millions of Refugees at Home", Migration Policy Institute, http://www.migrationinformation.org/profiles/ display.cfm?ID=424 (Retrieved on 2012-12-02).

Huseynov, J. (2008). The role of online communities in the development and formulation of Azerbaijani national identity. Paper presented at the meeting of the Association for the Study of Nationalities 2008 World Convention, Columbia University, New York.

Kelly, M. E. (1996) The Importance of Families and Communities in Understanding Ethnicity and Maintaining Ethnic Identity. Ethnic Studies Review. 19.1 (Feb 28,):1.

Retrieved from

ProQuest.,http://search.proquest.com/ethnicnewswatch/docview/215500852/fulltext/14 32AB00B55605DB990/1? accountid=11243

Kuo, B. C. H., \& Roysircar, G. (2004). Predictors of acculturation for Chinese adolescents in Canada: Age of arrival, length of stay, social class, and English reading ability. Journal of Multicultural Development and Counselling, 32, 143-154.

Malko, V. (2005) Language, culture, and pedagogy: Immigrants from the former Soviet Union studying English as a second language in California postsecondary institutions. Ed.D. dissertation, California State University, Fresno and University of California, Davis, Unpublished doctoral dissertation 
Mishory, J. (2006). "Azerbaijan deserves U.S. public attention." The Daily Bruin. Retrieved on November 8, 2013. http://dailybruin.com/2006/10/22/iazerbaijan-deserves-uspublic/

Mostofi, N. (2003). Who We Are: The Perplexity of Iranian-American Identity. The Sociological Quarterly, Vol. 44, No. 4 Autumn, pp. 681-670.

Murphy E. J, Mahalingam R. (2004). Transnational ties and mental health of Caribbean immigrants. Journal of Immigrant Health. Oct;6(4):167-78.

Naghiyeva Sh. \& Hasanov M. (2006). Ordinary and Unordinary America (in Azerbaijani). Baku, "Chinar-Chap".

Naoki, Ch.(2001), Iranians in the United States and Japan: self-imagery and individualcollective dynamics, (Ph.D. dissertation), University of Illinois at Champaign Urbana, Retrieved from ProQuest http://search.proquest.com/docview/251784064 .

$\mathrm{Ng}$, Ch \& Northcott, H. C. (2010). The Ethnic and National Identity of South Asian Immigrant Seniors Living in Edmonton, Canada. Canadian Ethnic Studies. 2010, Vol. 41/42 Issue 3-1, p. 131-156.

Pew Hispanic Center. Statistical portrait of the foreign-born population in the United States 2011. http://www.pewhispanic.org/files/2013/01/PHC-2011-FB-Stat-Profiles.pdf

Phinney, J. (2003). Ethnic Identity and Acculturation. In K. Chun, P. Ball, \& Marin, G. (Eds.), Acculturation: Advances in theory, measurement, and applied research (pp. 63 81) Washington, DC: American Psychological Association.

Phinney, J. S \& Ong, A. (2007). Conceptualization and Measurement of Ethnic Identity: Current Status and Future Directions. Journal of Counseling Psychology Vol. 54, No. 3, 271-281.

Phinney, J. S. (1990). Ethnic identity in adolescents and adults: Review of research. Psychological Bulletin, Vol. 108(3), 499-514.

Pigott, B. S \& Kalbach, M. A.(2005). Language Effects on Ethnic Identity in Canada. Canadian Ethnic Studies; 2005; 37, 2. p3-18.

Rivers, N. M. (2012). Longer Sojourners: The Complexities of Racial Ethnic Identity, Gender, and Generational Outcomes for Sub-Saharan Africans in the USA. International Journal of Population Research, Volume 2012, 14 pages. http://dx.doi.org/10.1155/2012/973745

Schönpflug, U. (2002). Acculturation, Ethnic Identity, and Coping. Online Readings in Psychology and Culture, 8(1).

http://scholarworks.gvsu.edu/cgi/viewcontent.cgi?article=1068\&context=orpc

Retrieved: 01/10/2014.

Somerville, K. (2008). Transnational Belonging among Second Generation Youth: Identity in a Globalized World. Journal of Social Sciences, Special Issue on Youth and Migration, 10: 23-33. Anand Singh (ed.).

Stephan, C. W., and W. G. Stephan. (2000a). The Measurement of Racial and Ethnic Identity. International Journal of Intercultural Relations 24: 541-552.

Su, T. F. \& Costigan C. L.(2009). The Development of Children's ethnic identity in immigrant Chinese families in Canada: The role of parenting practices and children's perceptions of parental family obligation expectations. The Journal of Early Adolescence, Volume 29 Number 5, 638-663.

Taylor, D. M.; Bassili, J. N. \& Aboud, F.E. (1973). Dimensions of Ethnic Identity: An Example from Quebec. The Journal of Social Psychology, Vol 89(2), Apr, 185-192. 
The Migrant Integration Policy Index (Mipex III) http://www.mipex.eu/usa

Thernstrom, S. \& Orlov, A., et al. (1980). Harvard Encyclopedia of American Ethnic Groups. Harvard University Press.

Uslu, R. \& Kocaman, S. (2013). The Activities of the Azerbaijani Diaspora in the United States of America. The 2013 WEI International Academic Conference Proceedings, pp.46-50.

Vaquera, E. \& Aranda E. (2011). "The Multiple Dimensions of Transnationalism: Examining their Relevance to Subjective Well-being." Special issue on migration and happiness. Journal of Social Research \& Policy, 2 (2): 47-72.

Vertovec, S. (2001). Transnationalism and identity. Journal of Ethnic and Migration Studies Vol. 27, No. 4: 573-582.

Vigdo, J.(2008). Measuring Immigrant Assimilation in the United States Manhattan

Institute for Policy Research, Civic Report, No. 53 May 2008, http://www.manhattaninstitute.org/html/cr_53_ai1.htm

Voutsinas, M.M. Ethnic identity in second generation immigrants: An examination of parenting styles and self-esteem. (Doctoral dissertation.) St. John's University, New York. Published by ProQuest LLC 2012. Retrieved from ProQuest http://search.proquest.com/docview/1170832438

\title{
Summary
}

\section{First generation Azerbaijani immigrants in the United States: socio- cultural characteristics and identity issues}

\author{
Ahmad Guliyev \\ George Washington University, USA
}

The community of Azerbaijani immigrants in the United States, which is the subject of our proposed study, is a pretty recent phenomenon. Most Azerbaijani-Americans have immigrated to the United States mainly from Iran, Azerbaijan, Russia or Turkey. Azerbaijani immigration and integration in the United States have not been documented and studied thoroughly.

There is no population survey that provides information of any kind on the attitudes and opinions of Azerbaijani Americans. Based on the survey conducted among sample of 103 Azerbaijani immigrants, this paper aims to provide the profile of the Azerbaijani community, socio-cultural characteristics, assess the immigrant's identification with their native culture, ethnic attachment, as well as, their emotional ties to the homeland and level of integration in the United States.

Keywords: Azerbaijani immigration, Azerbaijani Americans, Azerbaijani Diaspora, Migrants, Ethnic Identity. 